BMJ Open Sport \& Exercise Medicine

\title{
Document analysis of exertional heat illness policies and guidelines published by sports organisations in Victoria, Australia
}

\author{
Prasanna J Gamage (D) , Caroline F Finch (D) , Lauren V Fortington
}

\begin{abstract}
To cite: Gamage PJ, Finch CF, Fortington LV. Document analysis of exertional heat illness policies and guidelines published by sports organisations in Victoria, Australia. BMJ Open Sport \& Exercise Medicine 2020;6:e000591. doi:10.1136/ bmjsem-2019-000591
\end{abstract}

- Additional material is published online only. To view please visit the journal online (http://dx.doi.org/10.1136/ bmjsem-2019-000591).

Accepted 6 February 2020

\section{Linked}

- https://doi.org/10.1136/ bmjsem-2020-000774

\section{Check for updates}

(c) Author(s) (or their employer(s)) 2020. Re-use permitted under CC BY-NC. No commercial re-use. See rights and permissions. Published by BMJ.

School of Medical and Health Sciences, Edith Cowan University, Joondalup, Western Australia, Australia

Correspondence to Dr Prasanna J Gamage; p.gamage@ecu.edu.au

\section{ABSTRACT}

Objectives To conduct a document and content analysis of exertional heat illness (EHI)-related documents published by sports organisations in Victoria, Australia, in order to determine their scope and evidence base against current international best practice recommendations. Methods A qualitative document and content analysis. Official documents relating to EHI were identified through a search of 22 Victorian sport organisation websites, supplemented by a general internet search. The content of these documents was evaluated against recommendations presented in three current international position statements on prevention and management of EHI. Results A range of document types addressing $\mathrm{EHI}$ were identified ( $n=25)$, including specific heat policies, match day guides, rules and regulations. Recommendations about prevention measures were the most common information presented, but these were largely focused on event modification/cancellation guidelines only $(n=22 ; 88 \%)$. Most documents provided information on hydration as a preventive measure ( $n=20 ; 80 \%)$, but the emphasis on the importance of cooling strategies $(n=7 ; 28 \%)$ and heat acclimatisation $(n=5 ; 20 \%)$ was inadequate. Details on $\mathrm{EHI}$, including its definition, symptoms/signs to look out for, and common risk factors (beyond humidity/high temperatures) were lacking in most documents.

Conclusion There is considerable variation in formal documents with regard to their content and quality of information. Continued efforts to bridge the evidence to practice gap in sports safety are therefore important. This study highlights the challenge for community sport, which relies on high-level policy and governance, across settings and populations that can differ substantially in their needs.

\section{INTRODUCTION}

Exercising in hot and humid environments imposes a physiological strain on the cardiovascular and thermoregulatory systems of the body. ${ }^{1}$ Impaired thermoregulatory mechanisms during exercise result in a significant increase in core body temperature that can lead to exertional heat illness $(\mathrm{EHI}){ }^{2}$ Based on the International Classification of Diseases-Tenth Revision-Clinical Modification, EHI is categorised as part of the

\section{What are the new findings?}

- Most documents on heat illness related published by sports organisations in Victoria focused on three main areas - weather-related factors (ambient temperature), the importance of hydration and strategies for event modification/cancellation.

- Documents commonly missed information that is recommended in international best practice statements, in particular acclimatisation, cooling and recognition of signs/symptoms.

- In line with new and emerging evidence, most heat illness-related documents may need updating. Referring to local and international resources is recommended while acknowledging potential limitations and the requirement for updating.

external causes chapter, ranging from milder forms (heat oedema, heat rash, heat cramps, heat syncope) to more severe (heat exhaustion) and life-threatening conditions (heat strokes). ${ }^{3}$ All these conditions contribute to significant morbidity and mortality among sports participants. ${ }^{4}$ There is a growing body of epidemiological evidence that the incidence, number of hospital admissions and overall morbidity associated with sportsrelated EHI have increased over the last three decades. This is, in part, related to changes in diagnosing and coding of EHI in hospital settings. ${ }^{56}$

Risks and precipitating factors in developing EHI are well recognised. ${ }^{7}$ Further, $^{8}$ preventive measures such as heat acclimatisation, hydration and cooling strategies have been shown to be effective in managing and preventing EHI. ${ }^{9}$ Close monitoring of the environmental risks and hazards, identifying sports-related EHI risk factors in individuals, as well as implementing timely countermeasures are key steps in reducing morbidity and mortality associated with EHI. ${ }^{7-9}$ Due to the preventable nature of EHI, many national and international sports governing bodies 
have published policies, guidelines and consensus recommendations to prevent them. ${ }^{7-10}$

Over the last several decades, a gradual increase in environmental temperature has been observed globally ${ }^{11}$ and in Australia, ${ }^{12}$ where temperatures reaching more than $40^{\circ} \mathrm{C}$ during the summer are commonly experienced. ${ }^{12}$ Together with ambient temperature, environmental heat stress is primarily determined by relative humidity, solar radiation and air movement. All these four factors are taken into account in calculating wet bulb globe temperature (WBGT), which is probably the most widely used measure of heat stress. ${ }^{13}$ High relative humidity greatly reduces the evaporative heat loss capacity of the body, resulting in a rise in core body temperature. ${ }^{7}$ Heat-related health risks and adverse consequences are a significant concern in Australia, especially among individuals who engage in sports and physical activities. ${ }^{14}$ As with other areas of sports safety, ${ }^{15} 16$ the sports organisations in Australia have a duty of care to set policies and provide guidelines for safe participation in heat. A key agency for community sports in Victoria (a state of Australia) is VicSport, which serves as a central body for multiple sports organisations within the state. Sports organisations, through the leadership of VicSport, seek to promote safe participation in community sport settings.

In 2007, Sports Medicine Australia (SMA), Australia's sports medicine agency, developed and disseminated resources (Beat the Heat/UV and extreme weather guidelines) for sports organisations to use and adapt to their particular settings. ${ }^{17-19}$ The extent to which this advice has been used, adapted and otherwise incorporated into sports safety guidance is unknown. Further, several reviews in the literature have raised some concerns with regard to the amount of information provided in the sports safety-related documents and their level of quality. ${ }^{10} 20$ Therefore, the aim of this study was to assess the heat policies published by sports organisations in Victoria, Australia:

- First, by conducting a document analysis, which involves the systematic identification, retrieval and categorisation of documents. $^{21}$

- Second, by conducting a content analysis of these documents against current best practice items, extracted from three international position statements on heat in sport. ${ }^{7-9}$ Content analysis is a qualitative method that involves organising and evaluating information contained in a series of documents, in view of determining the scope and evidence base of the sports-specific resources. ${ }^{21}$

\section{METHODS}

\section{Document analysis}

Document search

Official documents relating to 'heat' (and its synonyms: hot, temperature, humid, humidity, weather, climate, environment), published on a Victorian state sport organisation website or directly linked to the state sport organisation (eg, published with branding) were sought

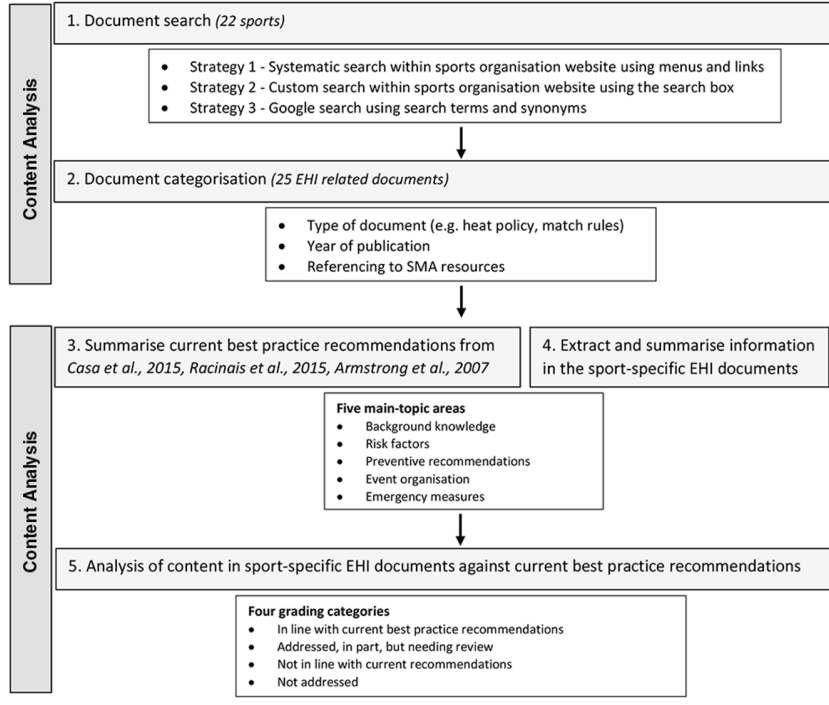

Figure 1 Diagrammatic illustration of the steps in conducting the document analysis and content analysis. EHI, exertional heat illness; SMA, Sports Medicine Australia.

(figure 1). EHI-related documents published by national sports organisations that were linked to state sport organisation's website were also included. Documents that were published in another format for clubs or competitions within Victoria, but not associated directly with the state sport organisation or their websites were not included in this analysis.

Twenty-two different sports were chosen for review, as they were included in a broader state government review of heat in sport to which this study contributed (https:// vicsport.com.au/hot-weather-resources). PJG undertook the document search and identification using a threestage approach as illustrated in figure 1 . The search was carried out in August 2016 and included documents published to that date. Where no website document was identified for a sport, two members of the research team (PJG and LVF) subsequently undertook further checks to confirm that none could be identified.

\section{Document categorisation}

Each of the EHI-related documents was reviewed and categorised based on their descriptive information, including the type of document (eg, policy, guideline, rules, and so on), the year of publication and whether referencing to SMA resources.

\section{Content analysis}

The second part of the study consisted of identifying the content in the EHI-related documents and evaluating the content against the current best practice recommendations (figure 1).

\section{Summarise current best practice recommendations}

Current best practice recommendations were extracted and summarised under five main topic areas and related subtopic areas from the three most recent published consensus and position statements on EHI. ${ }^{7-9}$ The first 
of these publications was the American College of Sports Medicine position stand on EHI during training and competition. ${ }^{8}$ The second publication was the American National Athletic Trainers Association position statement on $\mathrm{EHI},{ }^{7}$ and the third publication was the consensus recommendations by a panel of international experts on 'training and competing in the heat'. ${ }^{9}$ The five main topic areas and their subtopic areas that were identified from these three documents as being representative of key features relevant to EHI across sports settings included:

1. Background knowledge (subtopics: EHI definition and categorisation, EHI symptoms and signs).

2. Risk factors (subtopics: weather-related risks, intrinsic risks, extrinsic risks).

3. Preventive recommendations (subtopics: heat acclimatisation, hydration, cooling strategies, other preventive measures).

4. Event organisation (subtopics: event modification strategies, event cancellation strategies).

5. Emergency measures (first aid and treatment).

The data table in online supplementary file 2 provides a detailed list of content under each main topic and subtopic areas, which were subsequently used to analyse the content of the selected sport-specific EHI documents.

\section{Extract and summarise information in the sport-specific EHI documents}

Content in the selected sport-specific EHI documents was first examined by PJG and information was summarised under the same five main topic areas and subtopic areas as above.

Analysis of content in sport-specific EHI documents against current best practice recommendations

Summarised content of the sport-specific EHI documents was then analysed against the best practice recommendations (presented in online supplementary file 2) a by two members of the research team (PJG and LVF). In order to report both the scope and the level of agreement with the best practice recommendations, the content of the selected sport-specific EHI documents was graded under four categories (figure 1). These four categories were developed by the authors based on the study aim, that is, to determine the scope and evidence base of the sports-specific resources. Where required, items were discussed among the research team and decisions were made with consensus. For some items, it was difficult to determine which category documents fitted in clearly (eg, some information was presented that addressed part of the criteria, but not all elements). In these cases, the more cautious option was chosen (eg, 'needing review' rather than 'in line with current recommendations' or 'not in line with current recommendations'). This choice was made to illustrate the need for content to be reviewed, as opposed to stating that the content was incorrect.

\section{Patient and public involvement}

Patients and/or the public were not involved in the design, conduct, reporting, or dissemination plans of this research.

\section{RESULTS}

A total of 25 documents (range from 1 to 3 per sport) were identified from the 22 different sports selected for the analysis (table 1). No documents were identified from the websites for six sports (27\% of all sports). The year of publication of the documents ranged from 2004 to 2016. Nine documents (36\% of all identified documents) were published in the last 5 years (2012-2016). Nearly half of the documents $(n=11 ; 44 \%$ of all identified documents) included a link or recommendation to seek guidance from SMA; however, they did not always clearly specify to which of the three documents from SMA ${ }^{17-19}$ they were referring.

Figure 2 presents the grading of the content in the sport-specific EHI documents by main topic and their subtopics against the best practice recommendations. It can be seen that some recommendations are covered to a greater extent than others, and that no single document/s covered all recommendations.

\section{Background knowledge}

Details on what EHI is, including its definition and common symptoms/signs, were largely missing from most documents. Twenty documents $(80 \%$ of all identified documents) did not provide information on different EHI categories and their definitions. Information on background knowledge from the other five documents (20\% of all identified documents) was not in line with current recommendations. Symptoms and signs of EHI, which are important in recognising individuals suffering from EHI, were not described or explained in 18 documents ( $72 \%$ of all identified documents).

\section{Risk factors}

Twenty-two documents ( $84 \%$ of all identified documents) highlighted weather-related risk information as the major contributory factor in developing EHI. Ambient temperature was considered in almost all documents as the major weather-related risk. However, the impact of intrinsic risks (ie, risks related to the individual; eg, age, fitness level, level of acclimatisation) and extrinsic risks (ie, risks not related to the individual; eg, clothing, protective gear, playing surfaces, time and duration of play) was only addressed in 13 (52\% of all identified documents) and 6 (24\% of all identified documents) of documents, respectively.

\section{Preventive recommendations}

Hydration, as a preventive measure, was addressed in 20 $(80 \%)$ of documents and seven of those were in line with best practice recommendations. Different cooling strategies such as application of ice towels and water, cold water immersion, fanning (external cooling methods), 
Table 1 Heat-related documents published on the websites of sports organisations in Victoria

\begin{tabular}{|c|c|c|c|c|}
\hline Sport & Document title & Type of document & Year & Reference to SMA* \\
\hline Athletics & - & - & - & - \\
\hline Australian football & $\begin{array}{l}\text { 1. Junior football match guide } \\
\text { 2. Country heat and cold policy } \\
\text { 3. National extreme weather policy }\end{array}$ & $\begin{array}{l}\text { National match guide } \\
\text { State policy } \\
\text { National publication }\end{array}$ & $\begin{array}{l}- \\
2007 \\
2013\end{array}$ & $\begin{array}{l}\text { SMA website/guidelines } \\
- \\
-\end{array}$ \\
\hline Baseball & 4. Heat policy & State policy & 2007 & - \\
\hline Basketball & $\begin{array}{l}\text { 5. Climate policy } \\
\text { 6. Country heat policy } \\
\text { 7. By-laws/participant protection }\end{array}$ & $\begin{array}{l}\text { State policy } \\
\text { State policy } \\
\text { State participant protection } \\
\text { by-laws }\end{array}$ & $\begin{array}{l}2009 \\
2007 \\
2009\end{array}$ & $\begin{array}{l}- \\
- \\
-\end{array}$ \\
\hline Bowls & $\begin{array}{l}\text { 8. Rules for competition } 2016 / 2017 \\
\text { 9. } 2015-2016 \text { Metropolitan Saturday } \\
\text { pennant conditions of play }\end{array}$ & $\begin{array}{l}\text { State competition rule } \\
\text { changes } \\
\text { State letter to metropolitan } \\
\text { clubs }\end{array}$ & $\begin{array}{l}2016 \\
2015\end{array}$ & - \\
\hline Cricket & $\begin{array}{l}\text { 10. Club assist well played } \\
\text { 11. Cricket Australia junior cricket } \\
\text { policy } \\
\text { 12. Extreme heat guidelines }\end{array}$ & $\begin{array}{l}\text { National/community } \\
\text { publication } \\
\text { National publication } \\
\text { State policy/guidelines }\end{array}$ & $\begin{array}{l}2016 \\
2004 \\
-\end{array}$ & $\begin{array}{l}\text { SMA website } \\
\text { SMA website/local guidelines } \\
\text { Smartplay, SMA (VIC) }\end{array}$ \\
\hline Cycling & $\begin{array}{l}\text { 13. Extreme weather policy and } \\
\text { guidelines }\end{array}$ & State policy & - & - \\
\hline Football & $\begin{array}{l}\text { 14. Extreme weather policy } \\
\text { 15. Indoor hot weather policy }\end{array}$ & $\begin{array}{l}\text { State policy letter to match } \\
\text { officials } \\
\text { State policy letter to match } \\
\text { officials }\end{array}$ & $\begin{array}{l}2009 \\
2011\end{array}$ & $\begin{array}{l}\text { SMA website/'Beat the heat' } \\
\text { SMA 'Hot weather guidelines' }\end{array}$ \\
\hline Golf & 16. Hot weather guidelines & National guidelines & 2010 & $\begin{array}{l}\text { SMA 'Beat the heat', 'Hot } \\
\text { weather guidelines', 'UV exposure } \\
\text { \& heat illness guide' }\end{array}$ \\
\hline Hockey & 17. Heat advice & State advice & 2015 & $\begin{array}{l}\text { SMA 'Beat the heat' and 'Hot } \\
\text { weather guidelines' }\end{array}$ \\
\hline Indoor sports & 18. Extreme heat guidelines & State guideline & - & Smartplay, SMA (VIC) \\
\hline Life-saving & 19. Hot weather guidelines & - State policy & 2011 & SMA website \\
\hline Little Athletics & 20. Extreme weather policy & State policy & 2015 & - \\
\hline Netball†‡ & - & - & - & - \\
\hline Rugby league & $\begin{array}{l}\text { 21. Heat guidelines (attachment to } \\
\text { competition rules and regulations) }\end{array}$ & - State (or national) guidelines & 2017 & SMA (SA) \\
\hline Rugby union & - & - & - & - \\
\hline Softball & $\begin{array}{l}\text { 22. Inclement weather policy } \\
\text { 23. Hot weather guidelines }\end{array}$ & $\begin{array}{l}\text { State policy } \\
\text { National policy }\end{array}$ & $\begin{array}{l}2009 \\
2011\end{array}$ & $\begin{array}{l}\text { SMA website } \\
\text { SMA (SA) }\end{array}$ \\
\hline Surfing & - & - & - & - \\
\hline Swimming†‡ & - & - & - & - \\
\hline Tennis & 24. Extreme weather policy & - National policy & 2014 & - \\
\hline Triathlon†‡ & - & - & & - \\
\hline Volleyball & 25. Extreme heat policy & - State policy & 2014 & - \\
\hline
\end{tabular}

Online supplementary file 2 provides information related to internet links of the documents.

Sports Medicine Australia (SMA) is a national body but previously operated as a federation of state-based branches. Where documents referred specifically to documents published by those earlier state-based SMA branches, this is indicated as Victoria (VIC); South Australia (SA); ultraviolet (UV). Cells marked as '-' where documents were not found.

${ }^{*}$ Referred to or provided links to SMA heat guidelines, resources and their website.

†Links identified within sports websites to SMA hot weather guidelines, Smartplay, SunSmart UV and heat guidelines.

$\ddagger$ No documents found. Secondary search undertaken to confirm no documents could be located.

ingestion of cold fluids or ice slurry (internal cooling methods) and the importance of heat acclimatisation for prevention of EHI were not addressed (18 in cooling strategies; 20 in heat acclimatisation) in the reviewed documents.

\section{Event organisation}

Most ( $\mathrm{n}=22 ; 88 \%$ of all identified documents) documents recommended one or more strategies for event modification (12 documents fully in line with current recommendations, 10 documents addressed this in part 


\begin{tabular}{|c|c|c|c|c|c|c|c|c|c|c|c|c|c|c|c|c|c|c|c|c|c|c|c|c|c|c|}
\hline Main-topic & Sub-topic & 1 & 2 & 3 & 4 & 5 & 6 & 7 & 8 & 9 & 10 & 11 & 12 & 13 & 14 & 15 & 16 & 17 & 18 & 19 & 20 & 21 & 22 & 23 & 24 & 25 \\
\hline \multirow[t]{2}{*}{ Background knowledge } & EHI definition \& categorisation & $\mathrm{x}$ & $x$ & $\mathrm{x}$ & $\mathrm{x}$ & $x$ & $x$ & $x$ & $\mathrm{x}$ & $x$ & $x$ & $x$ & $\mathrm{x}$ & & $x$ & $x$ & $x$ & & $\mathrm{x}$ & $\mathrm{x}$ & & & $x$ & & $x$ & $x$ \\
\hline & EHI symptoms and signs & $x$ & $x$ & & $x$ & $x$ & $x$ & $x$ & $\mathrm{x}$ & $x$ & $x$ & $x$ & & $x$ & $x$ & $\mathrm{x}$ & $x$ & & & $\mathrm{x}$ & $\mathrm{x}$ & & $x$ & & & \\
\hline \multirow[t]{3}{*}{ Risk factors } & Climatic risks & & & & & & & & & & & & & & & $\mathrm{x}$ & & & & & & & & & & \\
\hline & Intrinsic risks & & $x$ & & & $\mathrm{x}$ & $\mathrm{x}$ & $\mathrm{x}$ & $\mathrm{x}$ & $x$ & $\mathrm{x}$ & $x$ & & & $\mathrm{x}$ & $\mathrm{x}$ & & $x$ & & & & & & & & $\mathrm{x}$ \\
\hline & Extrinsic risks & $x$ & $x$ & $\mathrm{x}$ & $x$ & $x$ & $x$ & $x$ & $\mathrm{x}$ & $x$ & $x$ & $x$ & & $x$ & $\mathrm{x}$ & $x$ & & $x$ & & $\mathrm{x}$ & $\mathrm{x}$ & & $x$ & & & $x$ \\
\hline \multirow{4}{*}{$\begin{array}{l}\text { Preventive } \\
\text { recommendations }\end{array}$} & Heat acclimatisation & $\mathrm{x}$ & $x$ & $\mathrm{x}$ & $x$ & $\mathrm{x}$ & $\mathrm{x}$ & $x$ & $\mathrm{x}$ & $x$ & $\mathrm{x}$ & $\mathrm{x}$ & $\mathrm{x}$ & & $x$ & $\mathrm{x}$ & & $\mathrm{x}$ & $x$ & $\mathrm{x}$ & & & $\mathrm{x}$ & & $\mathrm{x}$ & $\mathrm{x}$ \\
\hline & Hydration & & & & & & $\mathrm{x}$ & & $x$ & $x$ & & & & & & & & & & $x$ & & & & & & $x$ \\
\hline & Cooling strategies & $\mathrm{x}$ & $x$ & & $x$ & & $\mathrm{x}$ & & $x$ & $x$ & $\mathrm{x}$ & $x$ & $\mathrm{x}$ & & $\mathrm{x}$ & $\mathrm{x}$ & $\mathrm{x}$ & $\mathrm{x}$ & $x$ & $\mathrm{x}$ & $\mathrm{x}$ & & & & $\mathrm{x}$ & $x$ \\
\hline & Other preventive measures & $\mathrm{x}$ & $x$ & & & & $\mathrm{x}$ & & $\mathrm{x}$ & $x$ & $\mathrm{x}$ & $x$ & & & & $\mathrm{x}$ & & & & $\mathrm{x}$ & & & & & & $x$ \\
\hline \multirow[t]{2}{*}{ Event organisation } & Event modification strategies & & & & & & & & & & $\mathrm{x}$ & $x$ & $\mathrm{x}$ & & & & & & & & & & & & & \\
\hline & Event cancellation strategies & & & $\mathrm{x}$ & & & & & & & & $\mathrm{x}$ & & & & & & & & & & & & & & \\
\hline Emergency measures & First aid and treatment & $\mathrm{x}$ & $x$ & $\mathrm{x}$ & $\mathrm{x}$ & & $\mathrm{x}$ & & $\mathrm{x}$ & $\mathrm{x}$ & $\mathrm{x}$ & $x$ & & & $x$ & $\mathrm{x}$ & & $\mathrm{x}$ & & $\mathrm{x}$ & & $\mathrm{x}$ & & & & $\mathrm{x}$ \\
\hline
\end{tabular}

Figure 2 Coding of the content in the sport-specific EHI documents against best practice recommendations. EHI, exertional heat illness.

only) and cancellation (10 documents fully in line with current recommendations, 12 documents addressed this in part only) on days of extreme heat. A scoring system to guide event modification and/or cancellation decisions based on a checklist was used in two sports, where most extrinsic risks (eg, temperature, time of the event, duration and intensity of activity, venue and surface type) and intrinsic risks (acclimatisation status, fitness level, age, medical conditions) were taken into consideration.

\section{Emergency measures (first aid and treatment)}

Information on what to do in case a participant displayed signs and symptoms of EHI was not adequately covered. In terms of early recognition of different EHI conditions, first aid and emergency care for these conditions was not detailed in 15 (60\% of all identified documents) of the EHI documents.

\section{DISCUSSION}

There has been an increasing concern shared by sports organisations on weather change and global warming, and its effects towards developing EHI. In order to disseminate information on EHI risk mitigation to their communities, sports organisations need to understand the latest evidence related to EHI in sports. The present study identified EHI-related documents published by sports organisations in Victoria and analysed their content by rating them against an extract of current international recommendations. ${ }^{7-9}$ Findings highlighted the gaps and limitations in existing Victorian sports organisations' official EHI documentation. Most documents focused on three main areas: (1) weather-related parameters as major risks, primarily referring to ambient temperature ( $n=22$ documents; $84 \%$ of all identified documents); (2) the importance of hydration in preventing EHI $(n=20$ documents; $80 \%$ of all identified documents); and (3) event modification and cancellation strategies $(n=22$; $88 \%$ of all identified documents). Most EHI documents were not comprehensive enough to provide current best evidence and, given their age, they may need reviewing. Importantly, this study found that there is a need for EHI policies to be updated in line with emerging scientific evidence.
The recent international consensus recommendations mainly focused on three main preventive measures for EHI: heat acclimatisation, hydration and cooling strategies. ${ }^{9}$ It is recommended for athletes to undertake exercise in a euhydrated state and minimise body water deficits through proper rehydration during exercise. ${ }^{9}$ In the present analysis, most documents provided a good account on hydration in preventing EHI, detailing the type, volume and timing of fluid intake. This most likely reflects the fact that 'hydration' has long been a general topic in sports science, for preventing of EHI and for improving performance ${ }^{22}$ and cognitive functions. ${ }^{23}$ Nonetheless, the most suitable fluid intake strategies and recommendations should be made based on the playing context and availability of additional resources such as medical trained personnel. ${ }^{24}$ For example, elitelevel athletes can benefit from having a 'programmed drinking' strategy (eg, calculating specific fluid volumes per kilogram body mass). ${ }^{25}$ On the other hand, 'ad libitum drinking' (consumption of fluid to thirst) can be a suitable recommendation for community sporting context where resources may not be available for advance fluid intake strategies. ${ }^{26}$

In contrast to the hydration issue, which was well covered in the documents, there was far less emphasis on heat acclimatisation and cooling strategies. At the community-level sport participation, simple cooling strategies such as fanning air, application of cold towels, ingestion of cold fluids or ice slurry and resting in shade or access to air-conditioned rooms during the breaks can be effective in reducing the risk of EHI. ${ }^{9}$ For individuals with suspected heat stroke, immediate whole body cooling is strongly recommended before transporting to a hospital, in order to minimise morbidity and mortality. ${ }^{7-9}$ Current evidence shows the importance of structured heat acclimatisation sessions for athletes (ideally for 2 weeks using a comparable degree of heat stress as the target competition) to gain complete physiological adaptations and maximum benefits. ${ }^{9}$ These recommendations were not addressed in most documents included in this study. Within the context of community sport participation, it is difficult to consider the role of heat acclimation. For elite athletes, well-structured heat acclimatisation 
strategies can be implemented with the resources available at elite level. Therefore, recommendations in policy documents should be tailored to suit the playing context and availability of resources. If possible, heat acclimatisation programmes can be incorporated into participants' training by coaching staff, when they expect to compete in hot environments. ${ }^{7-9}$ Where not feasible, players and staff should be additionally mindful of risk.

Defining and recognising early forms of EHI are discussed in recent literature. ${ }^{27}$ Clarity on EHI definitions is important for accurate diagnosis of different forms of EHI and recognising their severity. The topic areas related to categorising and defining different EHI conditions, symptoms and signs to assist with early recognition, and first aid and treatment were not commonly addressed in the reviewed documents. A number of documents presented background information referring to more severe forms of EHI, such as heat exhaustion/ heat stroke, but no mention of milder forms such as muscle cramps, heat rash and heat syncope was provided. Knowledge and awareness in these milder forms among sports participants, coaches and event organisers are important, especially as warning signs can be recognised through player monitoring, allowing treatment timely measures to be implemented. ${ }^{728}$ Therefore, the specific recommendations in the current documents could be expanded to ensure that they contain up-to-date information for recognising and managing early forms of EHI, thus avoiding progression to more severe and fatal forms such as heat stroke. ${ }^{2}$

Fewer than half of the documents included in this study presented a clear, evidence-informed strategy for event organisers to determine the level of risk when faced with a decision towards enacting event modification or cancellation measures. Where this strategy was in place, the event modification or cancellation decision was based mainly only on weather-related parameters and cut-off values, largely relying on ambient temperature and, to a lesser extent, WBGT. The weather data can be easily obtained through online resources such as the Bureau of Meteorology website (www.bom.gov.au), and therefore widely used by event organisers and serve as important indicators in making event modification/cancellation decisions. However, due to other multiple interacting factors that are associated with developing EHI, it is important not to rely solely on weather parameters (eg, WBGT, ambient temperature) ${ }^{9}$ For example, Cricket Australia has updated their heat policy in 2019 and introduced a Heat Stress Risk Index that includes two personal parameters (clothing, activity) relevant to cricket in addition to four environmental parameters (https:// www.cricketaustralia.com.au/cricket/rules-and-regulations). Similarly, the National Rugby League (NRL) uses a checklist with many weather and non-weather parameters to gauge EHI risk (https://www.playrugbyleague. $\mathrm{com} /$ policies).

These weather indices do not account for metabolic heat production associated with exercise workload or individual characteristics of the athletes. ${ }^{9}$ The rate of metabolic heat production in the body during exercise is related to the intensity and duration of physical activity (workload) ${ }^{29}$ and therefore, a significant variation can be observed among different sports due to their different physical demands. ${ }^{30}$ In addition, some factors related to an individual participant, such as their body morphology, ${ }^{31}$ level of physical fitness ${ }^{31}$ and acclimatisation state, can also influence the development of EHI. ${ }^{32}$ Therefore, it would be useful for sports organisations to review their current guidelines and consider including non-weather-related factors where appropriate in making event modification or cancellation decisions.

The variability in the quality of recommendations, and complexity in providing evidence-based information to the community has been demonstrated in an earlier review. ${ }^{20}$ Findings of our study were consistent with this earlier review where hydration (fluid intake), weather parameters (heat limits) and event modification (precautionary interventions) were commonly presented as heat illness prevention themes. ${ }^{20}$ Other research into sports safety policy and guideline development in Australia has demonstrated both the advantages of such processes as well as the challenges that sports organisations face when developing and implementing local-level safety policies and practices. ${ }^{15} 3334$ This reflects the current situation in Australia where a large number of resources for safety promotion in sports are available, but can often overlap in their focus and therein cause confusion. ${ }^{10}$ One previous effort against the proliferation of inconsistent information about EHI to sports organisations in Australia has been the publication of general guidelines by SMA. ${ }^{17-19}$ Of the 25 documents reviewed in this study, 11 had incorporated the SMA guidelines and refer to their website and related resources. However, very few of them had specifically adapted the SMA guidelines to match their sport and playing characteristics. While SMA guidelines provide a comprehensive account on EHI for Australia, and were disseminated along with the intent that sports organisations should adapt the information to match their specific sporting context and setting, limitations in these documents should be acknowledged (eg, particularly in making generalised recommendations based on weather parameters) ${ }^{35}$ Further, a recent analysis of the limitations in the content of SMA resources, concluded there is a compounded problem when sports organisations rely on those as their source of guidance. This puts a particular onus on sports medicine bodies to always make sure that their resources, developed with the intent that they will be used by sports bodies and other third parties, are kept fully up to date and are updated in a timely manner when new evidence is available. For example, the Australian NRL has used the SMA documents as a guide to develop their own risk grading system to recognise high-risk circumstances, and has recommended risk mitigation and preventive measures. 


\section{Limitations}

The main purpose of using the three consensus recommendations was only to guide the content analysis of heat policy documents against updated guidelines. However, this does not assure the accuracy of the content in these threeo consensus documents, or the need for including the content in the current heat policies and guidelines. Similarly, the differences in content and quality of information observed in the different documents and sports do not merely suggest they are incomplete or incorrect. Further, the study does not suggest that policy documents related to heat should include all related details for every sport in a same manner. Rather, documents should include information relevant to the type of sports and playing context while including the most important evidence-based preventive and risk mitigation measures relevant to the context. With evolving scientific evidence, the best practice can change.

The content in the reviewed EHI documents was assessed against international position statements on EHI, although it is recognised that the Australian sports setting might have different requirements due to different sports and weather conditions. The primary document search was carried out by only one person, and secondary search was limited to the sports where no documents were found during the primary search. Only the first author was involved in summarising the best practice recommendations from the two position and consensus statements, and extracting and summarising information from selected sport-specific documents. A second author was involved only in reviewing the content in the sport-specific documents against the best practice recommendations. Due to these reasons, there could be potential bias in document selection, data retrieval and analysis. The sample of 22 sports included represents a large number of the major sports in Victoria, however, results may not be generalisable to other sports.

\section{CONCLUSIONS}

In most instances, the reviewed documents aimed to provide recommendations on preventive measures and event modification countermeasures to mitigate EHI. This is in line with the objectives of the international recommendations (consensus and position statements) on preventing EHI. However, considerable variation in the documents was observed with regard to the specific content and quality of information on different aspects. Few documents were comprehensive enough to address all aspects considered in the main topic areas and subtopic areas from definitions, risks, preventive measures, event modifications to treatment. Most documents focused on only three aspects: weather parameters as major risk factors, the importance of hydration and event modification strategies. With the projected ongoing weather changes in Australia and globally, and their potential for adverse health impacts on all those who play sports, a stronger and more consistent approach towards the prevention of EHI is required. Continued efforts to bridge the evidence to practice gap in sports safety are therefore important. This study highlights the challenge for community sport, which relies on high-level policy and governance, across settings and populations that can differ substantially in their needs.

Twitter Prasanna J Gamage @PrasannaGamage_, Caroline F Finch @CarolineFinch and Lauren V Fortington @lfortington

Acknowledgements Aspects of this research are related to the work of the Australian Centre for Research into Injury in Sport and its Prevention (ACRISP) at Edith Cowan University. ACRISP is one of the International Research Centres for the Prevention of Injury and Protection of Athlete Health supported by the IOC.

Contributors All authors contributed to develop the study methodology. PJG and LVF contributed to the acquisition and analysis of the data. PJG drafted the first version of the manuscript. All authors contributed to interpreting the data and revising the manuscript, and approved the final manuscript.

Funding This work was supported in part by a grant from VicSport as a contribution to a larger project.

Disclaimer There was no influence from the funding agent into the design, analysis or reporting of the study.

Competing interests None declared.

Patient consent for publication Not required.

Provenance and peer review Not commissioned; externally peer reviewed.

Data availability statement Data are available upon reasonable request. All data relevant to the study are included in the article or uploaded as supplementary information.

Open access This is an open access article distributed in accordance with the Creative Commons Attribution Non Commercial (CC BY-NC 4.0) license, which permits others to distribute, remix, adapt, build upon this work non-commercially, and license their derivative works on different terms, provided the original work is properly cited, appropriate credit is given, any changes made indicated, and the use is non-commercial. See: http://creativecommons.org/licenses/by-nc/4.0/.

\section{ORCID iDs}

Prasanna J Gamage http://orcid.org/0000-0003-4565-1598

Caroline F Finch http://orcid.org/0000-0003-1711-1930

Lauren V Fortington http://orcid.org/0000-0003-2760-9249

\section{REFERENCES}

1 Tatterson AJ, Hahn AG, Martin DT, et al. Effects of heat stress on physiological responses and exercise performance in elite cyclists. $J$ Sci Med Sport 2000;3:186-93.

2 Howe AS, Boden BP. Heat-related illness in athletes. Am J Sports Med 2007;35:1384-95.

3 ICD-10 Version: 2016. Effects of heat and light. Available: https://icd. who.int/browse10/2016/en\#/T67 [Accessed 20 Jun 2018].

4 Finch CF, Boufous S. The descriptive epidemiology of sports/leisurerelated heat illness hospitalisations in New South Wales, Australia. J Sci Med Sport 2008;11:48-51.

5 Harmon KG, Asif IM, Maleszewski JJ, et al. Incidence, cause, and comparative frequency of sudden cardiac death in national collegiate athletic association athletes: a decade in review. Circulation 2015;132:10-19.

6 Maron BJ, Doerer JJ, Haas TS, et al. Sudden deaths in young competitive athletes: analysis of 1866 deaths in the United States, 1980-2006. Circulation 2009;119:1085-92.

7 Casa DJ, DeMartini JK, Bergeron MF, et al. National athletic trainers' association position statement: exertional heat illnesses. J Athl Train 2015;50:986-1000.

8 Armstrong LE, Casa DJ, Millard-Stafford M, et al. American College of sports medicine position stand. Exertional heat illness during training and competition. Med Sci Sports Exerc 2007;39:556-72.

9 Racinais S, Alonso JM, Coutts AJ, et al. Consensus recommendations on training and competing in the heat. $\mathrm{Br} J$ Sports Med 2015;49:1164-73.

10 Bekker S, Finch CF. Too much information? A document analysis of sport safety resources from key organisations. BMJ Open 2016;6:e010877. 
11 Hunter DJ, Frumkin H, Jha A. Preventive medicine for the planet and its peoples. N Engl J Med 2017;376:1605-7.

12 Special climate statement 48 - one of southeast Australia's most significant heatwaves. Bureau of Meteorology, 2014. Available: http://www.bom.gov.au/climate/current/statements/scs48.pdf [Accessed 12 Mar 2018].

13 Budd GM. Wet-bulb globe temperature (WBGT)-its history and its limitations. J Sci Med Sport 2008;11:20-32.

14 Townsend M, Mahoney M, Jones JA, et al. Too hot to trot? exploring potential links between climate change, physical activity and health. J Sci Med Sport 2003;6:260-5.

15 Poulos R, Donaldson A, Finch C. Towards evidence-informed sports safety policy for new South Wales, Australia: assessing the readiness of the sector. Inj Prev 2010;16:127-31.

16 Donaldson A, Hill T, Finch CF, et al. The development of a tool to audit the safety policies and practices of community sports clubs. $J$ Sci Med Sport 2003;6:226-30.

17 Beat the heat. Sports Medicine Australia (SMA), 2011. Available: http://sma.org.au/resources-advice/policies-guidelines/hot-weather/ [Accessed 12 Jun 2018].

18 UV exposure and heat illness guide. Sunsmart, 2010. Available: http://sma.org.au/resources-advice/policies-guidelines/hot-weather/ [Accessed Access date: 12 Jun 2018]

19 Hot weather guidelines. Sports Medicine Australia (SMA). Available: http://www.sport.unimelb.edu.au/images/ClubResources_47_ 1218144596.pdf [Accessed Access date: 30 Aril 2019].

20 Larsen T, Kumar S, Grimmer K, et al. A systematic review of guidelines for the prevention of heat illness in community-based sports participants and officials. J Sci Med Sport 2007;10:11-26.

21 Bowen GA. Document analysis as a qualitative research method. Qual Res J 2009:9:27-40.

22 Casa DJ, Stearns RL, Lopez RM, et al. Influence of hydration on physiological function and performance during TRAIL running in the heat. J Athl Train 2010;45:147-56.

23 Ganio MS, Armstrong LE, Casa DJ, et al. Mild dehydration impairs cognitive performance and mood of men. Br J Nutr 2011;106:1535-43.
24 Kenefick RW. Drinking strategies: planned drinking versus drinking to thirst. Sports Med 2018;48:31-7.

25 Sawka MN, Burke LM, Eichner ER, et al. American College of sports medicine position stand. Exercise and fluid replacement. Med Sci Sports Exerc 2007;39:377-90.

26 Cotter JD, Thornton SN, Lee JK, et al. Are we being drowned in hydration advice? Thirsty for more? Extrem Physiol Med 2014;3:18-32.

27 Laitano O, Michelle AK, Lisa RL. Common misconceptions in classic and exertional heat stroke. In: Périard JD, Racinais S, eds. Heat stress in sport and exercise. Switzerland AG: Springer Nature, 2019: 91-112.

28 Andersen J, Courson RW, Kleiner DM, et al. National athletic trainers' association position statement: emergency planning in athletics. J Ath/ Train 2002;37:99-104.

29 Mora-Rodriguez R, Del Coso J, Estevez E. Thermoregulatory responses to constant versus variable-intensity exercise in the heat. Med Sci Sports Exerc 2008;40:1945-52.

30 Fowkes Godek S, Godek JJ, Bartolozzi AR. Thermal responses in football and cross-country athletes during their respective practices in a hot environment. J Athl Train 2004;39:235-40.

31 Cleary M. Predisposing risk factors on susceptibility to exertional heat illness: clinical decision-making considerations. J Sport Rehabil 2007;16:204-14.

32 Périard JD, Racinais S, Timpka T, et al. Strategies and factors associated with preparing for competing in the heat: a cohort study at the 2015 IAAF world athletics Championships. Br J Sports Med 2017;51:264-70.

33 Donaldson A, Borys D, Finch CF. Understanding safety management system applicability in community sport. Saf Sci 2013;60:95-104.

34 Donaldson A, Leggett S, Finch CF. Sports policy development and implementation in context: researching and understanding the perceptions of community end-users. Int Rev Sociol Sport 2012;47:743-60.

35 Chalmers S, Jay O. Australian community sport extreme heat policies: limitations and opportunities for improvement. J Sci Med Sport 2018;21:544-8. 